Indicadores para a

\title{
(re) construção da Proposta Curricular do Ensino de Ciências no município de Rio Do Sul (SC): uma abordagem pela pesquisa-ação
}

Mateus de Andrade

Edson Schroeder

\section{Resumo}

O artigo apresenta uma pesquisa em desenvolvimento e tem como objetivo identificar e analisar as concepções de professores sobre ciência e ensino de Ciências. Com o conjunto das discussões e reflexões, pretende-se obter subsídios para a (re) construção da Proposta Curricular para o Ensino de Ciências do município de Rio do Sul (SC), considerando-se aspectos teóricos e metodológicos associados ao ensino de Ciências. Utilizamos como metodologia, a pesquisa-ação e, como instrumento para a coleta dos dados, empregamos um questionário diagnóstico semi-estruturado, dirigidos aos sete professores, além de sete encontros, gravados em vídeo, posteriormente transcritos. Como categorias de análise, utilizamos três dimensões do projeto educativo do professor: a dimensão conceitual, a dimensão didática e a dimensão psicológica. Buscamos, a partir das concepções e crenças dos professores, de forma compartilhada, refletida e fundamentada, encontrar formas para o desenvolvimento de subsídios para a (re) construção da Proposta.

Palavras-chave: ensino de Ciências, Alfabetização Científica, projeto educativo do professor.

\section{Abstract}

Indicators for the Syllabus Teaching Science Proposal (re) construction in the town of Rio do Sul (State of Santa Catarina): action-research approach 
The article presents an ongoing research and aims at identifying and analyzing teachers' conceptions about teaching science and the science itself. With the collection of discussions and reflections it is intended to gather elements in order to (re)construct the Syllabus Teaching Science Proposal in the town of Rio do Sul, in the State of Santa Catarina, considering theoretical and methodological aspects associated to Science teaching. The methodology used is action-research and for data collection, we applied a semi structured diagnosis questionnaire, directed to the seven teachers, as well as seven meetings recorded on video, which were all transcribed afterwards. As for the categories analysis, we relied on three spheres of the teacher's educative project: the conceptual sphere, the didactic sphere and the psychological sphere. Starting from teacher's conceptions and beliefs, in a shared way, we worked towards finding ways to develop elements for the Proposal's (re)construction.

Keywords: Science teaching, Scientific Literacy, teacher's educative project.

\section{Introdução}

A escolha do tema da pesquisa deu-se pela necessidade de se repensar o ensino de Ciências que vem acontecendo na Rede Pública Municipal de Rio do Sul (SC). De uma maneira geral, é consenso entre os pesquisadores, que este ensino vem passando por uma crise (Gil-Perez; Vilches, 2005; Fourez, 2003). Discute-se, por exemplo, as ações necessárias para que possíveis mudanças aconteçam, levando-se em consideração o importante papel dos professores neste processo, principais mediadores entre os conhecimentos da ciência e os estudantes. 0 tema em questão é delicado e complexo, portanto, precisa ser estudado de forma mais aprofundada. Entendemos que é por meio do envolvimento consciente entre os professores, os estudantes e o conhecimento, que se pode construir um projeto educativo com vistas a uma aprendizagem muito mais significativa por parte desses. A aprendizagem significativa trata-se de um processo em que o estudante promove reestruturações no pensamento a partir dos conhecimentos construídos em seu cotidiano, portanto, já estabelecidos de forma implícita (Pozo, 2005). Nas aulas de Ciências, estes conhecimentos poderão passar por processos de superação e mudanças a partir dos conhecimentos escolares (conceitos científicos).

O ensino de Ciências é capaz de favorecer, na prática, o aceso dos estudantes a um conjunto de conhecimentos com vistas a sua transformação em instrumentos de interlocução com a realidade. Essa condição implica transpor limites e dificuldades que nos leva a repensar o ensino de Ciências na escola e como compreendemos os estudantes, sujeitos que têm saberes, construídos em outros espaços que não o escolar. Isto implica em que os professores tomem consciência da necessidade de repensar o modo como se percebem professores de Ciências. 
Neste sentido, as concepções que os professores têm sobre ciência, ensino de Ciências e alfabetização científica, seus projetos educativos e a Proposta Curricular para o ensino de Ciências na Rede Municipal de Ensino são objetos de investigação da pesquisa que apresentamos. É fundamental trazer à discussão, temas que consideramos essenciais para a prática dos professores de Ciências, como o papel deste ensino na atualidade e sua relação com os processos de alfabetização científica, com vistas à formação dos estudantes. Desta maneira, as discussões tratarão, também, de fatores sociais, históricos e culturais, uma vez que, tanto, professores como estudantes fazem parte de contextos sociais que suscitam formas de pensar e agir bastante específicas. Portanto, entendemos que os professores constroem seus projetos educativos a partir desses contextos concretos e é por meio da explicitação dos seus projetos educativos que esperamos apreender suas concepções, procurando trazer à tona e aprofundar discussões relevantes e atuais sobre ensino, com implicações diretas sobre a Proposta Curricular para o ensino de Ciências da Rede municipal de Rio do Sul.

Neste sentido, julgamos a possibilidade de se promover reflexões e mudanças nos projetos educativos de professores, voltadas para o desenvolvimento de um ensino de Ciências na perspectiva do sujeito humano (estudante), suas relações com os elementos do mundo natural e tecnológico, com outros humanos e consigo mesmo. Ao mesmo tempo, interagindo em outros planos, como aqueles das relações simbólicas, quando cria representações que orientam e o situam em um mundo complexo do qual faz parte. Nessas relações simbólicas, apropriam-se de costumes, valores e hábitos estabelecidos pelo grupo social participante. Essa apropriação pode ser conflituosa, subordinando-o a falsas visões do mundo ou permitindo-lhe, pelos conhecimentos científicos, uma visão mais autônoma e crítica da sua realidade.

A Secretaria Municipal de Educação, partindo da reivindicação de professores de diferentes áreas, propôs a criação de um programa de ensino, que teve somente um momento de discussão, em junho de 2001 e teve a sua conclusão e publicação ao termino do mesmo ano. Somente em 2008 foi retomada a discussão para realmente se fazer uma Proposta Curricular abrangendo todas as áreas e disciplinas do ensino fundamental, que também foi elaborado de forma muito rápida - em apenas dois dias de encontros, sem discussões e reflexões mais aprofundadas.

Neste processo, foram alterados os conteúdos curriculares e os objetivos para os respectivos conteúdos, a partir de três eixos norteadores: os conteúdos conceituais, procedimentais e os atitudinais. No que diz respeito ao ensino de Ciências, o documento apresenta que esse ensino deve desenvolver a capacidade reflexiva dos estudantes, promovendo diálogos e discussões constantes, assim como comunicações orais, escritas dos resultados de 
trabalhos com os estudantes dos nove $\operatorname{anos}^{1}$ do ensino fundamental. A necessidade de se repensar conjuntamente a Proposta, partiu dos próprios professores de Ciências que fazem parte da Rede Municipal, por meio de um questionário semi-estruturado, aplicado no ano de 2009. Fazse necessária as mudanças nas grades curriculares, com o intuito de se desenvolver Propostas comprometidas com novas concepções de ciência, ensino e aprendizagem (Gil- Pérez, et al., 2005; Delizoicov; Angotti; Pernambuco, 2002)

Temos como pressuposto que a alfabetização científica deva acontecer em todos os níveis da educação básica, sobretudo no ensino fundamental. Nesse sentido, a alfabetização científica torna-se um dos pilares na formação dos estudantes (Chassot, 2001) e surge como uma forma de localizar e aguçar as limitações do conhecimento, proporcionando um distanciamento do conhecimento cotidiano, mas que, ao mesmo tempo, apresente o conhecimento científico como alternativa plausível para uma melhor compreensão do mundo no qual estão inseridos. Pode-se argumentar que, na verdade, o desenvolvimento desta capacidade só seria possível por meio do ensino das Ciências. Certamente todas as disciplinas têm um papel neste processo, entretanto, atenta-se para a necessidade de uma leitura de mundo (Chassot, 2008), que passa pela aprendizagem dos conhecimentos das Ciências Naturais, em um mundo constituído de representações, signos e instrumentos tecnológicos. Como resultado, seria de se esperar uma maior participação nos progressos gerados pelo conhecimento científico, bem como a participação nas discussões e decisões que afetam direta ou indiretamente a vida das pessoas. Considera-se, neste contexto, a valorização e o desenvolvimento dos muitos aspectos relacionados com a alfabetização científica no ensino fundamental e do ensino de Ciências em particular. A avaliação dos sistemas educacionais, a formação continuada do corpo docente, a utilização das tecnologias educacionais são ações fundamentais para a melhoria do ensino de Ciências que acontece nas escolas.

As razões pelas quais as coisas devem ser ensinadas deveriam ser discutidas e propostas para sua introdução no currículo da disciplina de Ciências. Evidentemente, para que isto ocorra é preciso expor os conhecimentos científicos e explicá-los para que sejam compreendidos por todos. Em se tratando de ensino de Ciências, se aceita cada vez mais a concepção de que é de pouco valor dispor de uma boa teoria, ou de um bom modelo, se ele não puder ser posto em prática. Outra questão importante se refere à contribuição valiosa do professor de Ciências no sentido de possibilitar ao estudante compreender que não há ciência neutra e nem conhecimentos que não estejam comprometidos com um determinado projeto político, pedagógico, social e histórico dos sujeitos (Oliveira, 1997).

${ }^{1}$ A variação da idade deve-se ao período de adaptação à lei $n^{\circ}$. 11.274 , de 06 de fevereiro de 2006, que aponta a obrigatoriedade da aplicação do Ensino Fundamental para nove anos, e o prazo até 2010 para que os sistemas de ensino se adaptem.

R. B. E. C. T., vol 4, núm 1, jan./abr. $2011 \quad$ ISSN - 1982-873X 
Na prática, o professor pode assumir diferentes papéis em sala de aula, conforme Pozo (2005) nos apresenta: podemos encontrar, por exemplo, o "professor provedor", que proporciona aos estudantes informação fatos e dados, mas também dá instruções ou aplica castigos e prêmios. Ele tem as respostas de que o estudante necessita. O "professor modelo" é aquele que apresenta modelos ilustrados, atitudes e posturas habilidades em atuar na sala de aula. Os estudantes se espelham nele para fazer as atividades propostas. Sem dúvida, neste caso, é um papel mais implícito do que explícito. O "professor treinador", que fala em detalhes o que os estudantes precisam fazer e saber para fazer. É um papel complementar do professor treinador. Pode prover informações sem treino, mas não ao contrário. Por sua vez, o "professor tutor" é aquele que deixa os estudantes responsáveis por parte da sua aprendizagem, mas necessita definir bem as metas e os objetivos de como alcançá-los. O tutor fala o que é preciso fazer e como fazer. Finalmente, o "professor assessor" seria aquele que deixa que os estudantes organizem seus próprios objetivos e metas, e planejem sua aprendizagem, mas com pontos já previamente pensados pelo professor. Para Pozo (2005), o fato que mais preocupa no que diz respeito ao fracasso escolar não são os estudantes reprovados, mais sim, os que passaram e não aprenderam quase nada.

Assim, é fundamental que o professor problematize algumas questões que sejam relevantes para seu projeto educativo e, sempre que possível, buscar as melhores características dos tipos de professores citados anteriormente por Pozo (2005) como, por exemplo: as informações do "professor provedor", os modelos ilustrados do "professor modelo", os detalhes para saber para fazer algo do "professor treinador", ou deixa estudantes responsáveis, com objetivos e metas bem definidos do "professor tutor", ou ainda deixar que o estudante estabeleça seus objetivos e metas a seguir como o "professor assessor".

O professor de Ciências por sua vez, ao promover uma leitura do mundo, estabelece elementos que partem do cotidiano dos estudantes, de modo que aquilo que aprendem e aprenderam na escola, tenha um significado mais "útil" e interessante, amplificando o processo de reconstrução e reorganização das suas concepções de mundo, frente aos conhecimentos científicos. Entende-se que o ensino de Ciências não pode ser uma disciplina que limite o estudante somente a pensar sobre o mundo natural ou sobre a humanidade e suas obras, mas sim um ensino que também promova dúvidas, conflitos, discussões e diálogos, tão necessários no processo de alfabetização científica.

Compreendemos que, possivelmente, muitos professores não tenham, de fato, analisado certas circunstâncias de suas aulas com a devida atenção, no que diz respeito ao planejamento, metas, objetivos, elementos constituintes de seus projetos educativos, além do real significado dos "conteúdos científicos" ou escolares, que fazem parte da Proposta Curricular do ensino de 
Ciências. Compreendemos ser importante percebê-los como instrumentos do pensamento, portanto necessitam ser problematizados com vistas ao desenvolvimento, pelos estudantes, de uma percepção mais crítica em seu processo de aprendizagem - um fenômeno que ocorre a partir dos conhecimentos cotidianos implícitos, segundo Pozo e Crespo (2009). O professor precisa estar atento a estas questões, para, desta forma, melhorar a forma pela qual organiza o seu próprio trabalho e o adéqua à sua proposta de ensino.

"O professor é visto como o agente catalítico cuja presença estimula e desafia os estudantes, que "jogam". Nesta perspectiva, o apêndice do êxito do desafio do professor é tornar-se desnecessário, é um suicídio profissional que só pode ser praticado pelos educadores que, em vez de fazerem a classe um palco para o seu happening, fazem dela a plataforma donde os jovens autônomos alçam vôo para outras galáxias!" (Lima, 1987, p.47, grifos do autor).

A ciência, de forma alguma, é ou pode ser entendida como algo acabado, absoluto, inquestionável. Na verdade, a ciência precisa nos auxiliar na interpretação do mundo onde vivemos e onde poderemos viver. Para que os professores possam transgredir fronteiras, como argumenta Chassot (2003), deve-se compreender que é possível mudar e implantar uma cultura científica nas escolas, nos adequando às transformações já ocorridas e nos adaptar a esse desconhecido e ao mesmo tempo fascinante e inevitável mundo novo. A partir dessas considerações preliminares, apresentamos as questões de partida da nossa investigação ${ }^{1}$ : quais as concepções sobre ciência e ensino de Ciências que fazem parte dos projetos educativos de professores da Rede Municipal de Ensino de Rio do Sul (SC)? Quais seriam as dificuldades concretas desses professores no planejamento, organização e desenvolvimento dos seus processos de ensino e que estratégias utilizam para a sua superação? Que entendimentos os professores possuem a respeito da Proposta Curricular para o ensino de Ciências na Rede Municipal de Ensino de Rio do Sul? Para o desenvolvimento do artigo, apresentamos os dados e as análises referentes ao primeiro questionamento.

A seguir, o desencadeamento das atividades realizadas conjuntamente com os professores de Ciências, com vistas a um processo reflexivo centrado em seus projetos educativos, construídos nas diferentes trajetórias profissionais, objetivando apresentar subsídios para o aprimoramento da Proposta Curricular para o ensino de Ciências da Rede Municipal de Ensino de Rio do Sul (SC).

\section{Procedimentos metodológicos}

${ }^{1} \mathrm{O}$ artigo apresenta recortes de uma pesquisa em desenvolvimento, com seu início no ano de 2009.

R. B. E. C. T., vol 4, núm 1, jan./abr. 2011

ISSN - 1982-873X 
A presente pesquisa se desenvolveu sob um enfoque qualitativo (Esteban, 2010), e para coleta e análise dos dados, utilizamos um questionário diagnóstico, semi-estruturado, aplicado no último semestre do ano de 2009, além dos sete encontros, realizados a partir do final do ano de 2009, que foram gravados e posteriormente transcritos ${ }^{1}$. A compreensão e os aprofundamentos, teóricos partindo dos temas em questão, desenvolveram-se de acordo com os questionamentos, discussões, depoimentos, enunciados pelos professores que fizeram parte do estudo.

O questionário diagnóstico semi-estruturado ofereceu uma série de informações ao pesquisador, constituindo-se em uma fonte rica fonte de dados, posteriormente analisados. Pesquisas elaboradas com base em questionários semi-estruturados são importantes, não porque respondem definitivamente a um problema, mas porque proporcionam uma melhor visão desse problema, das possíveis dificuldades na organização, planejamento das aulas ou até projetos educativos, conforme requer a pesquisa (Bauer; Gaskell, 2008).

Por meio de 11 questionamentos dirigidos aos professores de Ciências dos anos finais, aprofundaram-se questões no decorrer dos encontros periódicos, tais como: por que ensinar Ciências? Qual a importância de ensinar Ciências? Por que aprender Ciências? O que se entende por ciência? De que forma acontece o ensino de Ciências? Como são abordados os conceitos científicos na sala de aula? Como está sendo utilizada a atual Proposta Curricular para o ensino de Ciências? A etapa das discussões desempenhou o importante papel de reunir definições, angústias e perspectivas do grupo participante, buscando elaborar, divulgar e avaliar os resultados.

No caso apresentado nesta pesquisa, o número de professores de Ciências é pequeno: a Rede Pública Municipal de Ensino de Rio do Sul conta hoje (2010) com uma equipe de sete professores de Ciências, seis graduados em Ciências Biológicas, sendo que cerca de $80 \%$ são pósgraduados, em nível de especialização e um deles com mestrado em educação. Um dos professores da pesquisa ainda está completando sua graduação, em Ciências Biológicas. Destes professores, $50 \%$ obtiveram a sua graduação após o ano 2000. Na classificação da categoria funcional, dois professores são efetivos na Rede somando $34 \%$, os outros cinco professores são ACT (66\%). A participação direta dos professores envolvidos nas discussões auxiliou significativamente em um processo que Thiollent (2000, p. 66) caracteriza como capacidade de aprendizagem:

"Na pesquisa-ação, uma capacidade de aprendizagem é associada ao processo de investigação. Isto pode ser pensado no contexto das pesquisas em educação,

\footnotetext{
${ }^{1}$ A pesquisa obedeceu aos procedimentos éticos necessários e os sujeitos envolvidos autorizaram previamente no TCLE (Termo de Consentimento Livre e Esclarecido), a utilização dos dados.
} 
comunicação, organização ou outras. O fato de associar pesquisa-ação e aprendizagem sem dúvida possui maior relevância na pesquisa educacional, mas é também válido nos outros casos".

A pesquisa-ação é amplamente discutida e debatida, de forma sempre participativa e colaborativa em seu método qualitativo, sendo mais difundida e aplicada no campo da educação. $\mathrm{Na}$ presente pesquisa os professores de Ciências refletiram as suas próprias práticas, analisando também os seus projetos educativos de forma a reconstruí-los, sempre que fosse necessário.

Para se compreender as concepções que os professores tinham construído sobre ciência, ensino de Ciências e alfabetização científica que se efetiva no cotidiano escolar, fez-se necessário uma aproximação dessas concepções, bem como das crenças e valores, dos discursos utilizados, enfim, de como se processa a rotina escolar - os aspectos característicos que iremos encontrar no cotidiano da escola (Adriano, 1997; Mortimer, 2002).

A etapa dos encontros com os professores aconteceu em locais previamente estabelecidos, tendo seu início no primeiro semestre de 2010. Os encontros objetivaram o aprofundamento sobre tópicos essenciais relacionados ao ensino de Ciências, bem como ao projeto educativo dos professores pesquisados. Neste sentido, as respostas obtidas pelo questionário semi-estruturado inicial forneceram subsídios importantes para o planejamento e organização desses encontros.

As informações qualitativas aconteceram a partir de categorias de análise previamente definidas, tanto para a primeira como para a segunda etapa. Na divulgação dos resultados, foi garantida a identidade de cada participante, para que pudessem expor posicionamentos pessoais.

A partir da análise das respostas apresentadas pelos professores no questionário semiestruturado, que antecedeu os encontros, foi possível organizar um quadro de conhecimentos que forneceu as representações mais comuns que possuíam a respeito de questões relacionadas ao ensino de Ciências e à alfabetização científica de uma maneira geral. O questionário, de certa maneira, refletiu também alguns aspectos do projeto educativo dos professores investigados, o que se aprofundou nos encontros posteriores. Também permitiu construirmos um perfil, no que diz respeito a algumas questões associadas à profissão. O método descritivo e a confrontação dos dados têm como objetivos principais a descrição das características de determinada população ou fenômeno e pode estudar as características de um grupo (Gil- Pérez, 2005).

A metodologia de pesquisa-ação contemplou a forma participativa dos grupos, que se envolveram, reforçando ideias, organizando-as para a efetivação de um entendimento comum, compartilhando-se intenções sobre possíveis mudanças a serem geradas.

"Na pesquisa-ação os pesquisadores desempenham um papel ativo no equacionamento dos problemas encontrados, no acompanhamento e na avaliação das ações desencadeadas em função dos problemas. Sem dúvida, a 
pesquisa-ação exige uma estrutura de relação entre pesquisadores e pessoas da situação investigada que seja de tipo participativo" (Thiollent, 2000, p.15).

Durante a pesquisa, o pesquisador está determinado a ajudar a identificar possíveis problemas no sistema educacional. Neste sentido, pode-se propor em conjunto uma discussão sobre tais problemas, com vistas a mudanças em cenários já estabelecidos pelos envolvidos na pesquisa, incluindo o pesquisador neste contexto. O objeto de investigação nesse processo está delimitado pelas pessoas que estão envolvidas diretamente com os problemas encontrados e na procura de soluções, formas de melhorar algo que precisa ser repensado para ser reconstruído de maneira participativa e significativa para todos os agentes em questão. A pesquisa-ação não trata apenas de um simples levantamento de dados e problemas. Trata-se de uma investigação com objetivos de pesquisa muito bem constituídos e os objetivos de ação, com base em uma situação social e com problemas diferentes, com ações não limitadas, mas sempre em um contexto de uma espiral auto-reflexiva.

A partir de três categorias, previamente estabelecidas, organizamos as análises, a partir da perspectiva teoria e empiria, relacionando conceitos teóricos, concomitantemente com os dados coletados. Desta forma, procuramos identificar as relações que estes parâmetros estabeleciam entre si, com a intenção de compreendermos melhor o projeto educativo dos professores para o ensino de Ciências: a importância relacionada ao domínio conceitual da sua área do saber (a dimensão conceitual), o domínio dos recursos e estratégias que promovam o desenvolvimento (a dimensão didática) e, sobretudo, o conhecimento dos estudantes no que se refere às suas características psicológicas e sociais, ou seja, um sujeito que possui modos de pensar e perceber o mundo, motivações e necessidades (a dimensão psicológica). Buscamos, a partir das concepções e crenças, dos sete professores de Ciências de forma compartilhada e refletida, encontrar subsídios que pudessem contribuir na (re) construção da Proposta Curricular para o ensino de Ciências da Rede Municipal de Ensino de Rio do Sul.

Os encontros foram organizados pelo investigador, e também com a participação da Secretaria Municipal de Educação (SME/RS), que cedeu espaços e convidou formalmente todos os professores de Ciências que compõem o quadro da Rede Municipal de Ensino. Os encontros realizaram-se nos períodos matutino e vespertino e tinham uma duração aproximada de quatro horas. Ao todo, efetivaram-se, até o presente momento, sete encontros.

\section{Apresentação dos resultados e análises}


Frente ao fato de que a pesquisa ainda não foi finalizada e ao grande número de dados obtidos até agora, apresentamos a seguir recortes do que consideramos exemplar, relativo aos encontros que aconteceram nas seguintes datas: 18 de novembro de 2009, 26 de fevereiro de 2010, 15 de março de 2010, 05 de abril de 2010, 03 de maio de 2010, 14 de junho de 2010 e 19 de agosto 2010. Para efeitos de análise, neste artigo, optamos pela integração dos dados obtidos pelo questionário diagnóstico e pelas transcrições dos sete encontros com os professores de Ciências, a partir das três categorias de análise definidas.

No que diz respeito à dimensão conceitual, foi possível perceber, pelos depoimentos apresentados, concepções que os professores têm construído sobre o ensino que fazem, bem como como uma concepção de ciência inerente a essa construção: "Vejo ciência em tudo, tudo o que você faz em sua vida o seu próprio corpo humano, etc. É sem dúvida alguma, tudo o que faz parte da nossa vida". Outra professora assim manifestou-se: "O ensino de Ciências na escola é desprezado pelos outros professores, [...]. Eu acho que eles deveriam dar mais importância, pois a nossa disciplina é o dia-a-dia, as coisas práticas da vida". Um terceiro professor argumentou:

"O homem depende das Ciências, não vejo ciência somente na disciplina de Ciências, é fundamental na nossa vida, num todo. Somente quando aparece um problema na escola da nossa área é que o professor de Ciências é lembrado, por exemplo, como o problema da reciclagem na escola, lixo e poluição, mas sempre com uma visão distorcida voltada apenas para o lucro e não para a conscientização do aluno".

Percebemos que há um entendimento, entre os professores, de que o ensino de Ciências é importante, no entanto, necessita de uma maior valorização. A desvalorização é sentida por meio da postura dos docentes de outras áreas do conhecimento, ou mesmo de áreas afins, sem esquecer também da postura dos próprios estudantes. Esses dizeres também nos remetem a uma constatação - a de que o ensino de Ciências passa por uma crise, já discutida por Fourez (2003) entre outros pesquisadores na área:

"Os professores de Ciências são duplamente atingidos. Inicialmente, como todos os professores, eles têm de se "virar" face à crise da escola e à perda de poder e de consideração de sua profissão. Eles também têm que enfrentar questões próprias aos professores de Ciências. Pede-se a eles que mostrem efetivamente o sentido que pode haver no estudo de Ciências para um jovem de hoje. Ora, a formação dos licenciados esteve mais centrada sobre o projeto de fazer deles técnicos de Ciências do que de fazê-los educadores. Quando muito, acrescentou-se à sua formação de cientistas uma introdução à didática de sua disciplina. Mas nossos licenciados em Ciências, como nossos regentes de então, 
quase não foram atingidos, quando de sua formação, por questões epistemológicas, históricas e sociais. Seus estudos não estão muito preocupados em introduzi-los nem à prática tecnológica, nem à maneira como Ciências e tecnologias se favorecem, nem às tentativas interdisciplinares. Eles confundem freqüentemente tecnologia e aplicação das Ciências ou a aplicação de um sistema experimental" (Fourez, 2003, p.3, grifo do autor).

Possivelmente muitos professores de Ciências, ainda não percebem que também tem uma parcela de culpa, que certamente, não é pequena no que diz respeito a deixar que essa desvalorização do ensino de Ciências e o desinteresse aconteçam, sobretudo por parte dos estudantes. Nas falas anteriores dos professores, podem-se perceber importantes elementos que apontaram para seus projetos educativos, sobretudo no que dizia respeito aos objetivos do ensino, o papel dos professores, dos conteúdos e do estudante na aula de Ciências:

"Nós professores devemos ensinar mais coisas, além dos conteúdos didáticos, buscando o diferente, devo levar para o meu aluno coisas da atualidade, sem deixar os livros de lado, por ser um bom recurso a mais nas aulas. Mas, mesmo assim, alguns alunos não gostam da disciplina, o que às vezes nos desmotiva. Então eu penso, vou ensinar o conteúdo e pronto".

Muito embora a discussão girasse em torno da questão inicial: por que ensinar Ciências, os professores deram uma ênfase maior à dimensão conceitual, trazendo em suas argumentações uma valorização dos conteúdos que ensinam nas aulas de Ciências, obedecendo à lógica transmissão - recepção. No entanto, não explicitaram questões relacionadas à contextualização desses conteúdos, ou seja, o entendimento de que o ensino dos conceitos científicos unidos, por exemplo, à história da ciência poderiam auxiliar para que os seus estudantes compreendessem melhor a sua realidade e suas demandas. Um dos professores falou: "O importante é saber algo, nem que seja de cor, para depois fazermos a prova, sabendo se o aluno aprendeu algo do que foi passado". Segundo os professores, há muito o que ensinar:

"O que se ensina, está na Proposta de ensino de Ciências. O que se deve ensinar é muito mais importante do que, como ensinar e por que ensinar Ciências. $O$ que o aluno quer, não é tudo o que se tem para ensinar. Deve-se entender que tem coisas que o aluno deve saber. Por que ensinar? Já se sabe, e como ensinar? Você também sabe. O importante é o aluno saber algo, nem que vagamente. 
No desenvolvimento do encontro, um dos professores explicitou certo autoritarismo exigindo do estudante que ele saiba o que está sendo transmitido, não importando muito se compreendeu os conceitos ou não, ou mesmo se o estudante já tem um conjunto de percepções construídas. Mas, se conseguir reescrevê-los nas provas, como foi transmitido em sala de aula, parece que houve aprendizagem: "O interessante é que o aluno grave o que é Ihe passado. A coisa funciona mesmo assim, é eu aqui e o aluno lá". Outro professor, aproveitando sua oportunidade, tece seu comentário:

"Não tem escola boa, não tem professor bom, tem alunos que estudam. Só se consegue ensinar para aquele que quer aprender. Os conteúdos estão ali, nos livros na internet, os conhecimentos estão ali, para quem quiser. Quanto mais informação (conteúdos) ele tem mais conhecimentos ele terá".

Os conhecimentos produzidos pela ciência ajudam a pensar nosso mundo e suas possibilidades, contribuindo sobre nossas decisões, com vistas a alcançarmos uma melhor qualidade de vida, modificando o nosso cotidiano e ainda o nosso aprendizado, sobretudo quando os conhecimentos cotidianos não podem ajudar muito. Entende-se que no processo de alfabetização científica, os estudantes podem se tornar interessados pela linguagem científica e, com ela, se tornar mais conhecedores e críticos, percebendo que não somos o centro da natureza, mas parte integrante dela. No entanto, Chassot (2003; 2001) lembra que a importância do senso comum encontra-se nos saberes que podem extrair dos conhecimentos e que poderão ser utilizados na construção de novos conhecimentos científicos.

"Essa importância é destacada tanto para as pessoas que, usualmente, não têm acesso ao conhecimento científico, mas também para o universo de uma determinada comunidade. As discussões acerca dos conhecimentos não científicos se dão medidas na tentativa de fazer informações sobre a importância das construções intelectuais da ciência" (Chassot, 2008, p.85).

O conhecimento cotidiano de uma sociedade pode ser interpretado como senso comum onde o juízo é um entendimento, uma descrição, uma observação com o intuito de dar sentido a algo não muito bem definido. Torna-se um conhecimento normal, habitual, que é transmitido de geração para geração. $O$ senso comum quase sempre tem rótulos de um conhecimento que não é científico e, por isso, sofrem um preconceito pela maioria dos pesquisadores. O bom senso apresenta-se como sendo uma parte inseparável do senso comum, um sinônimo da "razão" por ter em sua essência o trabalho de discernir entre algo verdadeiro e falso, usando a razão, o raciocínio para solucionar problemas, encontrar respostas que serão verdades quase dogmáticas para a grande maioria das pessoas ao utilizarem o senso comum como uma resposta natural. 
Segundo Chassot (1994) é preciso que nós professores de Ciências, busquemos, cada vez mais, um ensino inserido na realidade onde o mesmo se realiza. Os nossos estudantes do ensino fundamental precisam aprender a fazer uma leitura do mundo em que vivem, com o auxílio desse constructo humano chamado de ciência. Neste contexto, compreende-se que os saberes escolares são essenciais para esta caminhada:

"Saber escolar é o saber que a Escola transmite; e a ação de "transmitir" já descaracteriza este saber, pois estabelece a diferença entre produzir $e$ transmitir. A Escola defronta-se com um duro questionamento quando se diz que a mesma não é produtora do conhecimento, e sim, reprodutora ou apenas transmissora do saber. A Escola não se diminui por transmitir o saber, se buscar fazê-lo dentro de uma maneira (re) contextualizada" (Chassot, 2008, p.209, grifos do autor).

O trabalho de professores é auxiliar os estudantes na compreensão e aprimoramento dos seus saberes cotidianos, com suas explicações simples da realidade da qual fazem parte. Então, ao delinear e problematizar tais saberes, os estudantes podem ser inseridos em processos de investigação mais amplos, propiciando novas formas de pensamento, experimentando e transformando conhecimentos já construídos no decorrer das suas vidas: "e então, na busca de contribuir para a satisfação das necessidades de conhecermos a Ciência, amealharmos subsídios para a facilitação das tarefas cometidas a professoras e professores: fazer a alfabetização científica" (Chassot, 2008, p.62).

"De modo geral, o desenvolvimento da compreensão da ciência depende de todos esses aspectos. Os professores devem criar um mosaico de atividades de Ciências para crianças do ensino fundamental, no qual o conhecimento e o entendimento se desenvolvam juntamente com procedimento científicos, com habilidades e com posturas para e na ciência" (Ward, et al., 2010, p.22).

Partimos do pressuposto de que a escola e o ensino de Ciências que nela acontece podem contribuir para a formação de homens e mulheres, desenvolvendo suas capacidades de perceberem o mundo da qual fazem parte de forma diferente e tomarem decisões com vistas ao bem comum e do planeta, ou seja, mudar a sua vida cotidiana para melhor.

"A ciência tem um papel importante nesse processo. Em uma época em que os estudantes passam seu tempo de formas passivas, muitas vezes sós, assistindo televisão, ouvindo musica ou jogando no computador, a ciência ensinada na 
escola proporciona uma oportunidade para a discussão e para o compartilhamento de ideias, tão cruciais para o desenvolvimento de habilidades comunicativas. É imperativo, agora mais que no passado, que essas oportunidades ocorram no nível fundamental e do ensino e que sejam desenvolvidas de forma sistemática ao longo do sistema educacional. Os estudantes devem desenvolver um entendimento solido da ciência e a capacidade de considerar evidências cientifica de maneira objetiva" (Ward, et al., 2010, p.15).

Entretanto, segundo Ward, et al. os currículos de Ciências do ensino fundamental têm se aproximado muito pouco da vida real, do cotidiano dos estudantes: a ciência é parte incondicional da cultura moderna, pois pode ampliar a imaginação e a criatividade dos jovens. Neste sentido, seus desafios são enormes. O autor evidencia o papel dos professores, mas apresenta uma questão: como é possível efetivarmos um ensino de Ciências mais significativo se muitos desses professores baseiam seu ensino pela lógica da transmissão dos conhecimentos, muitas vezes, apoiada unicamente no livro didático?

"O papel do professor é crucial nesse processo: "negligenciar as habilidades processuais significa que os alunos devem aceitar as ideias conforme forem transmitidas pelo professor ou pelo livro didático, e existem muitas experiências que mostram ser improvável que isso leve a algum entendimento" (Ward, et al. 2010, p.25).

Ao falarem dos conhecimentos cotidianos dos estudantes, o professor coloca esses conhecimentos e conceitos, como práticas do dia-a-dia de todos nós. Mas, no entanto, parece deixar claro que a relação dos valores atribuídos a esses conceitos cotidianos com os conceitos científicos é muito fácil de acontecer na mente dos estudantes, ao explicitar habilidades: "Unir o conhecimento cotidiano dos alunos e dos pais, ao conhecimento científico não é difícil, é normal do dia-a-dia e junto aparecem habilidades para a pesquisa bibliográfica (de livros ou da internet, etc.) se dá por consequência".

Pensando desse modo, entende-se que os estudantes têm uma fácil e boa compreensão dos conceitos científicos, abandonando muito facilmente os seus conceitos do seu cotidiano. Entretanto, sabe-se que essa transformação de conceitos, citada anteriormente, não acontece bem assim, uma vez que os professores precisam estar atentos às complexidades associadas aos conhecimentos sobre a natureza, à tecnologia e sociedade e, em função disto, lembrar que são construídos de forma gradativa pelos estudantes na medida em que vão desenvolvendo seu processo cognitivo. Carvalho $(1998$, p.13) expõe este aspecto da cognição humana: 
"É importante lembrar que o processo cognitivo evolui sempre numa reorganização do conhecimento, que os alunos não chegam diretamente ao conhecimento correto. Este é adquirido por aproximações sucessivas, que permitem a reconstrução dos conhecimentos que o aluno já tem. Assim, é importante fazer com que as crianças discutam os fenômenos que as cercam, levando-as a estruturar esses conhecimentos e a construir, com seu referencial lógico, significados dessa parte da realidade".

O modelo de ensino baseado na transmissão-recepção tem como pressuposto que uma comunicação eficiente garante uma transmissão de significados sem qualquer modificação no conteúdo. No entanto, muitos estudos têm mostrado que o estudante constrói um sentido pessoal às informações que o professor, textos e materiais instrucionais Ihes oferecem (Schroeder, 2008). Isso não diminui a importância dos procedimentos didáticos tais como contar, informar, expor, mostrar e demonstrar, mas esclarece suas possibilidades e limites (Aguiar, 1999). Este autor ressalta os aspectos que julga essenciais para um melhor entendimento de uma abordagem que considera adequada:

a) a participação ativa do estudante;

b) a consideração e respeito pelas ideias dos estudantes e a compreensão de que as suas visões de mundo podem dificultar a compreensão do conhecimento científico;

c) a percepção de que a ciência é uma construção humana, constituindo um corpo de conhecimentos histórico, social e culturalmente situado e que visa a criação de modelos interpretativos da realidade, validados pela comunidade cientifica.

O que nos parece consensual é o fato de se considerar a educação como agente do desenvolvimento na medida em que promove a atividade mental construtiva dos estudantes, tornando acessíveis os aspectos da cultura que são fundamentais para o seu desenvolvimento individual e social (Sole; Coll, 2004). Coll (2002), Schroeder (2008) argumentam que a alfabetização científica que fazemos na escola é uma etapa fundamental para que os estudantes possam ser auxiliados de forma sistemática, planejada e contínua facilitando o acesso desses a um conjunto de saberes e formas culturais. As aprendizagens são consideradas essenciais para que eles possam se transformar em pessoas adultas e desenvolvidas, com plenitude de direitos e deveres, na sociedade da qual fazem parte. Muito embora os estudantes sejam os principais responsáveis pela sua própria aprendizagem, não se pode deixar de considerar o processo de ensino como sendo um processo compartilhado, no qual recebem a assistência dos professores, que a ajusta conforme as suas necessidades, no sentido de torná-los progressivamente autônomos e competentes em suas capacidades na resolução de tarefas, na utilização de 
conceitos, etc. (Sole; Coll, 2004). Uma assistência planejada dos professores auxiliará os estudantes positivamente na construção de significados em torno dos conteúdos científicos. Schroeder (2008) ressalta o papel do professor como um profissional que deve estar atento sobre as peculiaridades psicológicas dos estudantes com relação à aprendizagem e capaz de promover um processo de ensino que lhes permita compreender de maneira mais completa os significados sociais e culturais implícitos nos conteúdos ensinados na escola. Neste sentido, de acordo com Pozo e Crespo (2009), Delizoicov, Angotti e Pernambuco (2002) e Campos e Nigro (1999) é fundamental, também, os professores formarem concepções adequadas sobre a ciência, à natureza do conhecimento científico e o seu ensino. O que se pretende é que os estudantes saibam utilizar os conhecimentos científicos como instrumentos que ofereçam novos significados e percepções sobre o mundo, criando outras possibilidades de interação com a realidade (Sforni, 2004). Com isto, almeja-se uma emancipação social e cultural, via formação científica, que possibilite uma compreensão da realidade muito mais completa e interessante. $O$ ensino de Ciências, neste contexto, tem um importante papel na formação dos estudantes, sobretudo se quisermos um ensino voltado para uma alfabetização científica verdadeiramente significativa para estes.

Uma formação mais adequada poderia despertar o interesse de muitos estudantes pela ciência, bem como o gosto por aprendê-la. Os conhecimentos científicos ensinados na escola, se considerarmos o seu valor e o seu sentido, muitas vezes estão afastados do cotidiano de grande parte dos estudantes. Estes conhecimentos pouco têm auxiliado os indivíduos a refletir e agir sobre suas questões cotidianas. O que se ensina na escola deve auxiliar na construção de uma cultura científica com vistas a um entendimento dos fenômenos do mundo físico, químico e biológico, dos aspectos ambientais necessários para a manutenção da vida, além da compreensão dos processos de produção do conhecimento humano e da tecnologia, suas aplicações, conseqüências e limitações (Gil-Pérez; Vilches, 2005; Sasson, 2003; Delizoicov; Angotti; Pernambuco, 2002; Astolfl; Peterfalvi; Vérin, 1998; Carvalho, 1998).

Os conhecimentos derivados das Ciências humanas e naturais devem ampliar as experiências dos estudantes na construção de concepções adequadas sobre o meio natural, social e tecnológico. Além disto, os professores precisam estar atentos às complexidades associadas aos conhecimentos sobre a natureza, à tecnologia e sociedade e, em função disto, lembrar que são construídos de forma gradativa pelos estudantes na medida em que vão desenvolvendo seu processo cognitivo. No entanto, pela argumentação dos professores, parece existir uma concepção que relaciona a aprendizagem e os conteúdos a partir de um viés linear do currículo de Ciências: "Existe uma sequência hierárquica de certos conteúdos, que deve ser obedecida [...]. Já aprendi e desaprendi, mas o que está na proposta e no livro é pra ser feito, seja de um jeito ou de outro". Outra professora confirma a concepção: 
"Nunca consegui terminar todos os conteúdos, porque se ligam a outros assuntos e acaba a tempo da aula. Mas é o mínimo para se passar e deve-se tentar passar tudo o que está na Proposta. Sei todos os conteúdos, de todas as turmas, mas não sou obrigado a dar tudo. Se faltou algo deveria continuar no ano seguinte".

Para Schroeder e Engelsdorff (2010, mimeo), o ensino de Ciências ainda é concebido de forma linear e fragmentado e os professores sentem dificuldades em estabelecer pontes entre as diferentes áreas do conhecimento. Este contexto não proporciona a visão da ciência como uma construção histórica, bem como interdisciplinar. Os autores argumentam que a construção dos conhecimentos científicos sempre esteve ligada aos componentes sociais, ideológicos, culturais e ambientais, influenciando significativamente o pensamento das pessoas que produziam e produzem este conhecimento. Neste contexto, ressaltamos o papel político, não neutro, do ensino de Ciências.

Entendemos que centrar um projeto educativo em uma única dimensão - neste caso, a dimensão conceitual, pode gerar equívocos. Por um lado, a concepção de que é preciso transmitir o máximo de conteúdos possíveis - dar "conta" do programa; por outro, o domínio limitado sobre determinados temas que fazem parte do programa pode fazer com que o professor os ignore ou banalize temas potencialmente significativos. Essas concepções, muitas vezes podem determinar, em sala de aula, uma postura muito mais autoritária. Existe uma lógica no processo de construção dos conhecimentos, com a participação efetiva dos estudantes e seus professores neste processo. Nestes termos, fará sentido os professores repensarem sua ênfase à dimensão conceitual.

A respeito da dimensão psicológica, no decorrer das discussões, três professores de Ciências fizeram argumentações interessantes, uma vez que se evidenciou o papel do estudante na aula de Ciências, ou seja, explicitou-se a dimensão psicológica envolvida: "O ideal seria poder trabalhar os conhecimentos cotidianos dos alunos ao conhecimento científico, fazendo mais sentido, ao mundo deles, para se ter uma aprendizagem". Outro professor assim se manifestou:

"Não uso o questionário do livro porque é muito difícil, faço minhas próprias questões e eles respondem muito bem, eles aprendem mais facilmente, porque as respostas aparecem nas provas. Essas questões têm que ser feitas na linguagem dos alunos, se não é como um faz de conta, você finge que ensina e eles que aprendem, sinto-me culpado por não fazer diferente. Ainda usam questionários até no ensino superior, porque é mais fácil e prático de se cobrar do aluno. Nossos alunos têm que ter conhecimentos, eles têm que saber, porque 
a sociedade exige que se tenham conhecimentos. Emprego tem, mas têm que se saber, é o mundo do conhecimento, vagas têm, mas poucos têm o conhecimento necessário".

Podemos perceber, também, muitos aspectos que julgamos importantes, diretamente relacionados aos estudantes: a de que o professor de Ciências precisa ter clareza da importância de se relacionar os conhecimentos científicos aos seus contextos sociais e, neste sentido, a consideração dos seus repertórios conceituais já construídos. Desta maneira, a mediação docente é fundamental para o desenvolvimento de uma aprendizagem mais significativa.

Enquanto "consumidores" habituais de ciência, é necessário conhecer não somente os principais produtos da cultura científica, mas ser capaz de utilizá-los para a análise dos problemas cotidianos, pessoais e sociais com vistas à tomada de decisões frente às demandas do seu cotidiano (Pozo, 2005; Pozo; Crespo, 2009). O estudante vem para a escola com conhecimentos adquiridos pelas experiências e as relações sociais que estabelece em seu dia-a-dia. Essas ideias construídas são o que se denomina de conhecimentos prévios ou cotidianos. As aulas de Ciências devem permitir que expressem livremente suas concepções, suas crenças, enfim, suas teorias de mundo. Borges e Moraes (1998, p.20), argumentam que "só podemos ter acesso a um conhecimento novo a partir daquilo que já sabemos". Desta forma, os estudantes têm a oportunidade de aprimorar seus conhecimentos quando se explicita o que já sabem e, assim, o professor os leva a pensar sobre suas teorias. Aprender Ciências é aprender a ler o mundo, pois a ciência é uma linguagem, alfabetizar-se cientificamente é aprender a linguagem que está escrita na natureza (Borges; Moraes, 1998; Chassot, 2003).

No que diz respeito às concepções de ciência dos professores, apresentamos a seguir vários depoimentos: "[...] ciência é o nosso dia-a-dia, é tudo o que vivemos desde que somos fecundados até morrermos. Tudo é ciência". "Sim, pois tudo está relacionado com a ciência, respiração, alimentação, corpo humano, meio ambiente, fatores climáticos, tudo tem que ser estudado, pesquisado isso é, e faz parte da ciência". "É extremamente importante [a ciência], pois viabiliza a nossa existência e vai de encontro com o nosso dia-a-dia, fazendo-se analisar o passado e projetando-se para o futuro". "Entendimento dos mais variados aspectos da vida, seja natural, social, infinitamente ampla em todo o processo de conhecimento da vida, "estudo da vida". "É um termo muito amplo, pois trata de vários temas e assuntos interligados, auxiliando as demais disciplinas com as suas especificidades, torna-se essencial para o desenvolvimento do ser humano, das sociedades e do planeta". Um professor assim argumentou:

"É o ramo do conhecimento que me interliga com o mundo da natureza viva, é através dos conhecimentos científicos que me coloco ou vivo junto com o desenvolvimento do mundo da ciência onde envolve os avanços cientificos, 'a própria vida'”. 
De acordo com Pozo e Crespo (2009) e Campos e Nigro (1999) é fundamental os professores formarem concepções adequadas sobre a ciência, à natureza do conhecimento científico e o seu ensino. Entendemos que a ciência, é uma construção humana, historicamente situada, implica em problematizações, críticas, crises e rupturas, por isso não é uma verdade acabada, absoluta e inquestionável; ela passa por mudanças, que acontece no decorrer da sua história e suas teorias são reconstruídas a partir de teorias já existentes. Assim, "a escola deve trabalhar com a ideia de que a própria ciência é provisória, de que é continuamente reconstruída - estamos sempre criando novos significados na tentativa de explicar o nosso mundo" (Carvalho, et al., 1998, p.13). Nesse contexto, o homem pode não apenas compreender melhor sua realidade, mas participar da sua transformação.

"[...] o conhecimento científico submete-se a um processo de produção cuja dinâmica envolve transformações na compreensão do comportamento da natureza que impedem esse conhecimento de ser caracterizado como pronto, verdadeiro e acabado, mesmo que as teorias produzidas constituam verdades históricas que têm fundamentado o homem de ciência para uma explicação dos fenômenos" (Delizoicov; Angotti; Pernambuco, 2002, p.66).

Face ao exposto, foi fundamental conhecer as percepções dos professores a respeito do que é ciência. De acordo com Garcia-Milà (2004), quando se pergunta a professores de ensino fundamental e médio o que é ciência, geralmente respondem que ela explica as teorias científicas que procedem dos resultados de experiências; que a ciência é baseada naquilo que se pode ver, tocar, sentir, etc. e não em preferências pessoais e opiniões.

A ciência dos dias atuais não pode ser mais entendida de forma absoluta ou imutável. A exorcização de parte da ciência se deu pelo cientificismo muito fortemente difundido nos tempos modernos, só que a crença exagerada na ciência a colocava como algo sempre benéfico, às vezes até divino. O mundo do conhecimento e da ciência foi e é construído por indivíduos que pensaram e escreveram a respeito de significados, materializando ideias que hoje são utilizadas por todos nós e para o desenvolvimento da própria ciência. Entretanto, muitas vezes esse desenvolvimento não traz somente benefícios, mas problemas para todos nós. Muitas definições sobre ciência podem ser encontradas, no entanto, recorremos às reunidas por Chassot (2008, p.64):

"Conhecimento atento e aprofundado de alguma "coisa" ou "conhecimento amplo adquirido via reflexão ou experiência", ou ainda, "conjunto de conhecimentos socialmente adquiridos ou produzidos, historicamente 
acumulados, dotados de universalidade e objetividade que permitem sua transmissão, e estruturados com métodos, teorias e linguagens próprias, que visam compreender $e$, possivelmente orientar a natureza $e$ as atividades humanas".

Assim, na tentativa de descrever o mundo natural cria-se uma linguagem para podermos interpretar e superar dificuldades em compreender o universo que nos cerca. Neste ponto, concordamos com Chassot (2008) quando argumenta sobre a ciência como linguagem, comparando-a com uma língua falada em outro país que não se conhece: portanto necessita-se saber falar, ler e também a pensar nessa língua. Agora pense na ciência como uma língua que precisa ser aprendida para poder modificar coisas, entender outras e viver melhor com todos esses conhecimentos construídos historicamente. Ao conceber-se a ciência como uma linguagem, passa-se a entender que para falar e ler essa linguagem é necessário ter sido alfabetizados para tais tarefas. E este desafio de alfabetizar cientificamente os estudantes por meio do ensino de Ciências é um trabalho a fazer, compreende-se não como um ensino fácil.

No entanto, segundo Lorenzetti e Delizoicov (2001) somente a escola, sozinha, não tem condições de alfabetizar cientificamente os seus estudantes, pois eles não aprendem automaticamente com completo êxito nas aulas de Ciências. Seria interessante se os professores, ao mostrarem os conhecimentos que a ciência produziu e produz, pudessem auxiliar na compreensão do mundo; o ensino de Ciências não deveria ser apenas mais uma "disciplina" na escola, mas cujos conhecimentos estão presentes no cotidiano de cada um dos estudantes. Como se pode perceber é fundamental o papel da alfabetização científica na atualidade e do ensino de Ciências nas condições concretas apresentadas em escolas.

A alfabetização científica abre caminhos para um ensino de Ciências menos excludente, menos apolítico, onde o aprendizado possa reconhecer a ciência como ela é e como foi construída historicamente por homens e mulheres que desenvolvem pensamentos e consolidam muitos conhecimentos científicos utilizados por todos nós, nesse mundo natural e cotidiano (CHASSOT, 2007). Mas ainda assim, estudantes e professores consideram os conhecimentos científicos e a ciência como algo complexo para sua compreensão e a sua real utilização.

No decorrer dos encontros, retomávamos as questões centrais e as construções elaboradas em encontros anteriores. Em alguns encontros, as discussões eram originadas a partir de leituras, trazidas pelo pesquisador e que inspiravam os processos de reflexão entre os professores, sempre tomando como suporte principal seus projetos educativos com as suas dimensões: conceitual, didática e psicológica. Neste sentido, por exemplo, em nossas discussões sobre ciência e ensino de Ciências, foi perceptível mudanças nos discursos dos professores, expressas em suas argumentações: "É realmente eu tinha uma ideia errada de ciência, agora vejo isso". Achava que a ciência era exata, até citava a matemática, mas agora eu penso diferente sobre isso". 
Outro professor, assim se manifestou:

"Esse texto é bom pra gente ver que tem gente que pensa diferente". A ciência fica muito diferente do que nós achávamos ser ciência. Vejo "que se consigo mudar os meus conceitos posso ajudar a mudar os conceitos dos alunos também".

Outra professora argumentou:

"Admito que eu não tinha essa ideia tão clara de que a ciência é construída. Achava que era mais sólida com suas teorias, fórmulas, testes e experiências. Quando o texto fala sobre o senso comum e o conhecimento científico, eu entendo assim: acabamos desmanchando o que os alunos pensam, para colocar o conceito científico".

Podemos perceber que alguns professores conseguiram expor parte das suas concepções construídas sobre o que significa ciência. Ao pensar-se sobre os dizeres, pode-se inferir que alguns têm uma compreensão ainda bastante rudimentar de ciência, ou porque não dizer, até mesmo ingênua. O professor, ao planejar suas aulas, pensa em atividades e oportunidades dos estudantes investigarem um tema que lhes interesse, despertando o gosto pela ciência, sem excluir as habilidades que possam desenvolver no decorrer do processo de alfabetização científica. Professores têm muitos desafios ao interpretar e explicar determinados conhecimentos científicos, procedimentos que possam colaborar no desenvolvimento de habilidades e atitudes superiores nos seus estudantes, contribuindo, assim, para a aprendizagem.

Ao longo de todo o processo, foram feitas várias considerações importantes relacionadas à ciência e sua natureza, bem como a abordagem da ciência no currículo do ensino fundamental. Os conhecimentos científicos ajudam a desenvolver uma compreensão dos procedimentos, o desenvolvimento de habilidades e atitudes dos estudantes para com a sua formação e aprendizagem, consolidando novas posturas diante da ciência. Entendemos que este é um desafio que transforma um modelo tradicional de ensino com vista a uma possibilidade mais criativa, respondendo as necessidades desses estudantes.

Com relação à dimensão didática, a questão que apresentamos foi: como ensinar Ciências? Nossa intenção era desenvolver discussões em torno das decisões didáticas, mudanças e análises sobre o desenvolvimento de atitudes e habilidades pelos estudantes, adequando e reformulando o que julgávamos mais uma importante dimensão do projeto educativo. Motivados por esta 
provocação, surgiram alguns posicionamentos: "Percebe-se que existe uma sequência de facilidades para se alcançar certas habilidades com os alunos, onde você não pode pulá-las".

"Deve-se sempre partir do mais simples para o mais complexo, veja só, por exemplo, quando fazemos um bolo, partimos dos ingredientes para então misturá-los e continuar a fazer o bolo. Não dá para pular etapas ou vir do mais difícil para o simples, assim se complica a cabeça dos alunos muito mais".

Voltamos à Proposta Curricular do município para verificarmos e avaliarmos o que já havia sido pensado sobre as dimensões procedimentais e atitudinais, já descritas no documento. Aos poucos, os professores reconheceram e retomaram diferentes questões relacionadas ao documento, posicionando-se, propondo e justificando, além de perceberem a necessidade de se pensar ajustes e mudanças. Compreenderam a importância desta discussão, abrangendo as relações dos professores com seus estudantes, na tentativa de desenvolver as habilidades e atitudes que podem e precisam adquirir, com a devida atenção às estratégias e recursos de ensino mais adequados para isto.

Ressaltamos, neste momento, o importante papel da mediação do professor, auxiliando os estudantes para a mudança que é sempre bem vinda. Ao refletir sobre os processos que conduziriam ao desenvolvimento de habilidades e atitudes, sobretudo sobre as estratégias de ensino, os professores acabaram percebendo o quanto são responsáveis pelo desenvolvimento da autonomia em sala de aula, com vistas à alfabetização científica. Uma professora assim se manifestou:

"Os alunos não conseguem entender os questionários do próprio livro, eu acho até que têm professores que não entendem, achando muito difícil. Como então um aluno vai desenvolver maiores habilidades? Se o próprio professor tem problemas assim, não consigo ver todas essas habilidades em desenvolvimento, acontecendo".

Percebemos algumas questões importantes, a partir dessas duas manifestações. A primeira, diz respeito ao processo de alfabetização científica: julgamos fundamental que seu início aconteça muito cedo, a partir da educação infantil. Este é um processo que se dá paralelamente às outras alfabetizações, período em que as crianças vão sendo gradativamente introduzidas no mundo das letras, dos números, das artes, da ciência. A segunda, diz respeito ao fato de que a alfabetização científica não se efetiva sem a contribuição e a participação de todas as áreas do conhecimento que fazem parte dos currículos escolares. Se um estudante não aprendeu a ler, como será possível compreender a linguagem da ciência? Sobre essas questões, procuramos repensar o conjunto de procedimentos e atitudes em novas proposições que tivessem uma maior abrangência, mas que, de certa forma, se tornassem mais objetivas.

R. B. E. C. T., vol 4, núm 1, jan./abr. $2011 \quad$ ISSN - 1982-873X 
A transdisciplinaridade ainda é uma prática muito pouco utilizada nas instituições de ensino, essas variações e relações entre várias disciplinas podem conseguir mudar a direção e o sentido do ensino de Ciências tradicional (Chassot, 2001). A tecnologia aliada ao ensino de modo geral vem a contribuir quando o professor tem direcionado esse uso com vistas a um complemento auxiliar para construção de conceitos. Mas não é só isso, quando o professor estabelecer uma relação com outras disciplinas de áreas afins, como, por exemplo, no caso de Ciências, procurando temas em comum com as disciplinas de Geografia, Português, História e muitas outras, enfatizando essa necessidade de reunir conhecimentos tornando o conteúdo mais interessante e abrangente para a participação dos estudantes.

Paralelamente, discutimos, também, estratégias de ensino, realmente úteis, para os professores e seus estudantes, caminhos interessantes para os estudantes seguirem, compreendendo e respeitando os diferentes níveis de aprendizagem do ensino fundamental (6으 ao 9o ano).

\section{Considerações Finais}

No decorrer da pesquisa, foi possível constatar que os professores começaram a preocuparse com questões importantes relacionadas ao ensino de Ciências, entre elas, a necessidade de se aprofundar a respeito da ciência como linguagem e construção humana, historicamente situada. Com esse aprofundamento, ampliar as discussões relacionadas à inserção da história da ciência, ao "fazer ciência" e suas implicações sobre a alfabetização científica em sala de aula, em contextualizar conceitos e conteúdos a partir de contextos cotidianos dos estudantes. No entanto, muitas vezes, o ensino de Ciências ainda passa tangencialmente às demandas e questões cotidianas, das coisas que acontecem na vida real desses estudantes.

Nesse contexto, as dificuldades de entendimento apresentadas pelos estudantes apontam para uma aprendizagem insatisfatória. Evidenciamos um ensino que possibilite o desenvolvimento de capacidades reais dos estudantes, integrando a complexidade das competências necessárias para a compreensão e resolução de problemas concretos. $O$ estudante, por sua vez, acaba por menosprezar os conhecimentos de sala de aula, valorizando seus conhecimentos cotidianos - não que um seja mais importante que o outro, no entanto, entendemos ser importante um processo de integração e (re) construção, com vistas a uma aprendizagem mais significativa.

No que diz respeito à suas concepções a respeito de ciência e ensino de Ciências, entendemos que os professores atuantes na Rede Municipal de Ensino de Rio do Sul (SC), têm 
cultivado um conjunto de concepções que foram expressas no questionário diagnóstico e nos sete encontros realizados. No conjunto das concepções, percebemos que há fragilidades no que se refere ao entendimento de ciência como uma construção humana, não neutra e historicamente situada, além das questões relacionadas ao entendimento do "fazer ciência", como atividade construtiva, possível em sala de aula, por parte dos estudantes. Há a necessidade de aprofundamento sobre essas questões e uma necessária discussão acerca das suas concepções sobre ciência.

Outra questão relaciona-se ao processo de educação continuada, que deve acontecer periodicamente, com a participação efetiva da coordenação geral e, claro, da universidade responsável pela formação de professores de Ciências na região. Nesses encontros de formação, entre os temas possíveis, colocamos em evidência os objetivos do ensino de ciências, os processos de alfabetização científica dos estudantes, concepção de ciência, ensino e aprendizagem, entre outros. As concepções estão sujeitas às superações e transformações e consideramos isso salutar. Entretanto, sugerimos e os professores passem por esse processo de forma compartilhada, nunca de forma isolada. Avanços e recuos necessitam ser conhecidos por todos e as possibilidades de construção, com vistas aos aperfeiçoamentos, só se justificam quando feitos por todos os envolvidos, tanto professores como os estudantes.

Adiantamos que os professores de ciências da Rede Municipal de Ensino estão desenvolvendo um bom trabalho, mesmo diante das dificuldades encontradas. A partir das nossas considerações, apresentamos algumas implicações que consideramos importantes e que podem subsidiar o processo de reconstrução da Proposta do ensino de Ciências da Rede Municipal de Rio do Sul:

a) a função mediadora dos professores de Ciências é determinante para o desenvolvimento dos estudantes, tanto no que diz respeito às aprendizagens como às motivações que os manterão centrados, mesmo diante das adversidades, comuns em sala de aula. Os estudantes se desenvolvem quando interagem com materiais disponíveis pela cultura, no entanto, as interações não são determinadas pelos recursos em si, mas pelos objetivos e metas de trabalho, definidos e socialmente determinados;

b) no que se refere à dimensão conceitual, as atividades e conhecimentos precisam transpor os limites da escola. Deve ser preocupação dos professores de ciências e seus estudantes a criação de conexões significativas entre a realidade social e os conteúdos escolares e entre esses e a realidade social. Muitas vezes, o ensino de Ciências ainda passa longe demais das demandas e problemas do cotidiano, das coisas que acontecem na vida real desses estudantes;

c) com relação à dimensão didática, os textos diversos, além dos livros didáticos também são importantes e necessitam estar presentes nas atividades escolares. Sua utilização 
auxilia os estudantes na compreensão das diferentes formas de representação utilizadas pela comunidade científica. Evidenciamos os registros escritos como importante habilidade científica; da mesma maneira os registros se transformam em importantes instrumentos de avaliação do desenvolvimento dos estudantes;

d) no que diz respeito à dimensão psicológica, sabemos que os estudantes têm características psicossociais peculiares, no entanto as atividades em sala de aula precisam estar baseadas no desenvolvimento de conhecimentos e habilidades comuns. Entre outras ações, isto é possível pelas atividades em equipes e as apresentações, nas discussões, pela resolução de tarefas ou outras atividades em que são incentivadas a agir de forma deliberada e constante com seus pares.

e) no processo da alfabetização científica faz-se necessário, também, que os estudantes sejam familiarizados com domínios de investigação, técnicas e instrumentos. Para isso é imperativo que a formação continuada auxilie os futuros professores na identificação de canais de comunicação entre os estudantes e o professor. Os professores necessitam estar atentos às dificuldades características que os estudantes enfrentam em suas atividades, como os procedimentos científicos são conduzidos, além do papel fundamental dos registros escritos, conforme já havíamos mencionado anteriormente.

f) assim como os alunos aprendem e necessitam ser auxiliados, os professores também precisam ser apoiados, no que se refere à sua profissão. Portanto, também necessitam de novos conhecimentos, assistência e feedbacks constantes. Muitas vezes, encontram-se isolados, até mesmo dos seus pares. Possíveis soluções incluem, necessariamente, a participação conjunta das escolas, Secretarias de Educação e universidade. Muitas ações neste sentido já são levadas a cabo, entretanto, ainda há problemas de diferentes ordens, como por exemplo, resultados ainda incipientes no que diz respeito aos reflexos dos esforços empreendidos nos cursos de formação continuada, no dia-a-dia dos professores, sobretudo dos professores de Ciências.

g) no processo de apropriação da cultura científica, os alunos vão construindo, em atividades compartilhadas, seus conhecimentos, processo que se estende e se intensifica nas aulas de ciências. Todavia, insistimos, isso se dá nas situações de ensino em que professor e seus estudantes encontram-se engajados em processos ativos para o desenvolvimento da intelectualidade. Isso significa uma compreensão, por parte dos professores de que os estudantes precisam ser continuamente provocados para a resolução de tarefas com seus desafios associados, bem como nos procedimentos para a sua resolução desses desafios. Os dados obtidos em nossa pesquisa indicam que muitos professores valorizam os recursos e metodologias que conduzem a estes patamares de 
aprendizagem, mas alguns, ainda encontram dificuldades em organizar seus processos de ensino, prejudicados pela falta de recursos financeiros e materiais, formação, tempo e, até mesmo, dificuldades em lidar com estudantes que necessitam de apoios mais específicos.

Entendemos a urgência de pensarmos e discutirmos a Proposta de forma recorrente, com a participação e o envolvimento de todos os sujeitos nesse complexo e difícil processo de (re) construção. Nestes termos:

"a alfabetização científica pode ser considerada como uma das dimensões para potencializar alternativas que privilegiam uma educação mais comprometida. É recomendável enfatizar que esta deva ser uma preocupação muito significativa no ensino fundamental, mesmo que se advogue a necessidade de alterações quase idênticas também no ensino médio" (Chassot, 2003, p.29, grifo do autor).

Pretendemos, com o desenvolvimento da Proposta Curricular para o ensino de Ciências, considerar a alfabetização científica como uma importante etapa na formação dos estudantes. Uma Proposta Curricular desta envergadura não pode ser construída de forma isolada, mas sim, com a participação refletida e comprometida dos professores de Ciências.

\section{Referências}

Adriano, M. E. D. A. A pesquisa no cotidiano escolar. In: Fazenda, I. C. A. Metodologia da pesquisa educacional. 4 ed. São Paulo: Cortez, 1997.

Aguiar, O. Mudanças conceituais (ou cognitivas) na educação em ciências: revisão crítica e novas direções para a pesquisa. Química Nova na Escola, n. 9, mai., 1999.

Astolfi, J. P.; Peterfalvi, B.; Vérin, A. Como as crianças aprendem as ciências. Lisboa: Horizontes Pedagógicos, 1998.

Bauer, M. W.; Gaskell, G. 7 ed. Pesquisa qualitativa com texto, imagem e som: um manual prático. Petrópolis: Vozes, 2008.

Borges, R M. R.; Moraes, R. Educação em ciências nas séries iniciais. Porto Alegre: Sagra Luzzatto, 1998.

Campos, M. C. da C.; Nigro, R. G. Didática de Ciências: O ensino-aprendizagem como investigação. São Paulo: FTD, 1999.

Carvalho, A. M. P. de et al. Ciências no Ensino Fundamental: o conhecimento físico. São Paulo: Scipione, 1998.

Chassot, A. As Ciências Através dos Tempos. São Paulo: Moderna, 1994.

R. B. E. C. T., vol 4, núm 1, jan./abr. $2011 \quad$ ISSN - 1982-873X 
Alfabetização científica. 2 ed. ljuí: UNIJUİ, 2001.

Educação conSciência. Santa Cruz do Sul: EDUNISC, 2003.

Alfabetização científica: uma possibilidade para a inclusão social. Revista Brasileira

Educação, n.22, 2003. Disponível em:

http://www.scielo.br/scielo.php?script=sci_arttext\&pid=S1413- Acesso em: 12 de maio de 2010.

A. Sete escritos sobre educação e ciência. São Paulo: Cortez, 2008.

Coll, C. Aprendizagem escolar e construção do conhecimento. Porto Alegre: Artmed, 2002.

Delizoicov, D.; Angotti, J. A. A.; Pernambuco, M. M. Ensino de Ciências: fundamentos e métodos. São Paulo: Cortez, 2002.

Esteban, M. P. S. Pesquisa qualitativa em educação: fundamentos e tradições. Porto Alegre: Artmed, 2010.

Fourez, G. Crise no ensino de ciências? Investigações em ensino de ciências, v.8, n.2, 2003.

Disponível em: <http://www.if.ufrgs.br/ienci/?go=artigos\&idEdicao=26> Acesso em: 03 de maio de 2009.

Gil-Pérez, D.; Vilches, A. Importância da educação científica na sociedade actual. In: Cachapuz, A. et al. A necessária renovação do ensino das ciências. São Paulo: Cortez, 2005.

Gil-Pérez, D.; et al. Superação das visões deformadas da ciência e da tecnologia: um requisito essencial para a renovação da educação científica. In: Cachapuz, A. et al. A necessária renovação do ensino das ciências. São Paulo: Cortez, 2005.

Lima, O. L. Pedagogia: Reprodução ou Transformação. São Paulo: Brasiliense, 1987.

Lorenzetti, L.; Delizoicov, D. Alfabetização científica no contexto das séries iniciais. v.3, n.1, jun. 2001. Disponível em:

<http://www.portal.fae.ufmg.br/seer/index.php/ensaio/article/viewArticle/35> Acesso em: 06 de novembro de 2009.

Mortimer, E. F. Uma agenda para a pesquisa em educação em Ciências. Revista Brasileira de Pesquisa em Educação em Ciências, v. 2, n. 1, p. 25-35, 2002.

Oliveira, M. K. Vygotsky. Aprendizado e desenvolvimento: Um processo sócio-histórico. São Paulo: Sipione, 1997.

Pozo, J. I. Aquisição de conhecimento. Porto Alegre: Artmed, 2005. 
Pozo, J. I. Crespo, M. Á. A Aprendizagem e o ensino de ciências: do conhecimento cotidiano ao conhecimento científico. 5a ed. Porto Alegre: Artmed, 2009.

Sasson, A., et al. Cultura científica: um direito de todos. Brasília - DF - Brasil:

CNPq/IBICT/UNESCO, 2003.

Schroeder, E. A teoria histórico-cultural do desenvolvimento como referencial para análise de um processo de ensino: a construção dos conceitos científicos em aulas de ciências no estudo de sexualidade humana. 2008. 388 f. Universidade Federal de Santa Catarina, UFSC - Florianópolis, 2008. Tese de Doutorado.

Schroeder, E.; Engelsdorff, K. Ciência e ensino de ciências: a percepção dos professores dos anos iniciais da Rede Municipal de Ensino de Blumenau. 2010 (mimeo).

Sforni, M. S. de F. Aprendizagem conceitual e organização do ensino: contribuições da Teoria da Atividade. Araraquara: JM, 2004.

Solé, I.; Coll, C. Os professores e a concepção construtivista. In: $\mathbf{O}$ construtivismo na sala de aula. 6 ed. São Paulo: Ática, 2004.

Thiollent, M. Metodologia da Pesquisa-Ação. 10 ed. São Paulo: Cortez, 2000.

Ward, H.; et al. Ensino de Ciências. 2 ed. Porto Alegre: Artmed, 2010.

Mateus de Andrade. Rede Municipal de Ensino de Rio do Sul. Professor na Rede Municipal de Ensino de Rio do Sul. Mestrando no Programa de Pós-Graduação em Ensino de Ciências Naturais e Matemática - PPGCIM/FURB. biodeandrade@bol.com

Edson Schroeder. Fundação Universidade Regional de Blumenau. Professor titular do Departamento de Educação e professor pesquisador no Programa de Pós-Graduação em Ensino de Ciências Naturais e Matemática - PPGCIM/FURB. Doutorado em Educação Cientifica e Tecnológica pela Universidade Federal de Santa Catarina edi.bnu@terra.com.br 